\title{
Association of normal blood pressure with mouth shape
}

\begin{abstract}
The purpose of current learning was to co-relate regular blood pressure with shape of mouth. Total of approximately 200 persons were contributed in the present study. Blood remains supplied around body in pipes known as plasma vessels. The pushing of heart retains moving plasma through these vessels. Blood pressure (BP) is actually quantity of pressure in the walls of containers named arteries. Hypertension is another name of high blood pressure which can extremely unsafe if remain untouched. Blood pressures (BP) is very serious disorder and vary from time to time and affected by many factors like sleep, medicines, alcohol etc. The normal blood pressure has range less than $130 / 85 \mathrm{mmHg}$. For the measurement of blood pressure, we took a digital Blood Pressure (BP) apparatus called sphygmomanometer and measure the blood pressure of 200 students of Baha Uddin Zakariya University, Multan, Pakistan. We prepared a questionnaire to find the interaction between the normal blood pressure with the shape of mouth. We questioned that, what is your mouth shape? From persons and provided choices Oval and Round. It was concluded that the blood pressure had no scientific relation with the shape of mouth.
\end{abstract}

Keywords: blood pressure, association, mouth shape
Volume 9 Issue 3 - 2019

\section{Muhammad Imran Qadir, Muhammad Kashan Javed}

Institute of Molecular Biology and Biotechnology, Baha Uddin Zakariya University, Pakistan

Correspondence: Muhammad Kashan Javed, Institute of Molecular Biology and Biotechnology, Baha Uddin Zakariya University, Multan, Pakistan, Email kashanjaved0I@gmail.com

Received: March 02, 2019 | Published: June 21, 2019

\section{Introduction}

Blood remains supplied around body in pipes known as plasma vessels. The pushing of heart retains moving plasma through these vessels. Blood pressure (BP) is actually quantity of pressure in the walls of containers named arteries. ${ }^{1}$ Hypertension is another name of high blood pressure which can extremely unsafe if remain untouched. Blood pressure (BP) is very serious disorder and varies from time to time and affected by many factors like sleep, medicines, alcohol etc. The normal blood pressure has range less than 130/85mmHg. The upper blood pressure is called systolic which have normal range is $120 \mathrm{mmHg}$ and lower blood pressure is called diastolic which ranges $80-90 \mathrm{mmHg}{ }^{2}$

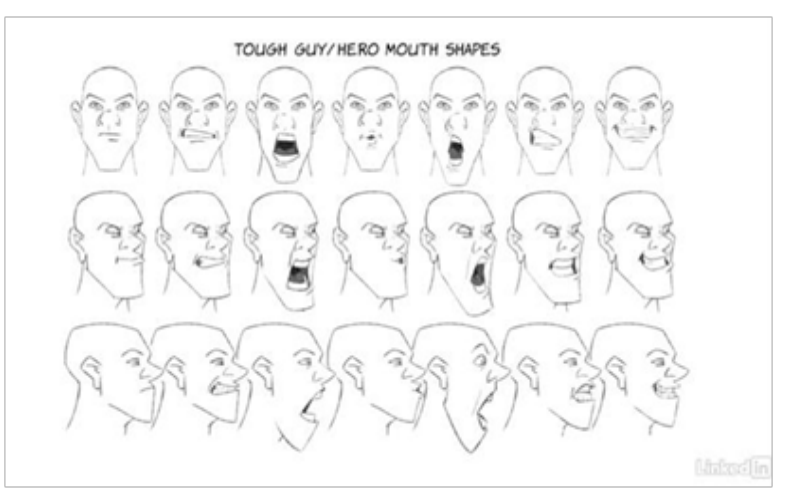

There are various forms of mouth like smiling mouth which remains smile at every time. These kinds of persons love to smile. Sad mouth which remains sad in every situation. ${ }^{3}$ There are other main forms of mouth called as round mouth and oval mouth. Round mouth is round shaped and oval mouth is like oval shaped also called as egg like mouth. Other types of mouth are lined shaped mouth. ${ }^{4}$ The person with this kind of mouth remain busy. Penniless mouth is another form of mouth. The person with this mouth shaped is dangerous and back biter.

The purpose of present learning was to find the interaction between regular blood pressure with the shape of mouth.

\section{Material and method}

Total of approximately 200 Persons were contributed in present study.

For the measurement of blood pressure, we took a digital Blood Pressure (BP) apparatus called sphygmomanometer and measure the blood pressure of 200 students of Baha Uddin Zakariya University, Multan, Pakistan. Then we wrote the measured blood pressure on the paper and made table of Systolic and Diastolic Blood Pressure Separately. ${ }^{5}$

A survey was set to find the interaction between the blood pressure and the shape of mouth. We questioned that, what is the shape of your mouth? From persons and provided choices Oval and Round

\section{Statistical analysis}

Statistical investigation was made with the help of MS Excel, $t$-Test and SAS (Statistical Analysis Software)

\section{Result and discussion}

Interaction of regular blood pressure with the shape of mouth is given in Tables $1 \& 2$. From table 1 and 2 it was clear that the blood pressure had no scientific interaction with the shape of mouth. A survey was set to find the interaction between the blood group and mouth shape. ${ }^{6}$

Table I Normal Blood Pressure (Systolic) in respect to Mouth Shape (Average \pm SD)

\begin{tabular}{llll}
\hline Gender & $\begin{array}{l}\text { Round shaped } \\
\text { mouth }\end{array}$ & $\begin{array}{l}\text { Oval shaped } \\
\text { mouth }\end{array}$ & p-value \\
\hline Male & $125.88 \pm 13.86$ & $135.33 \pm 15.54$ & 0.08 \\
Female & $118.07 \pm 13.70$ & $115.87 \pm \mid 1.24$ & 0.39 \\
Combined & $121.97 \pm 5.52$ & $125.6 \pm 13.76$ & 0.59 \\
\hline
\end{tabular}


Table 2 Normal Blood Pressure (Diastolic) in respect to Mouth Shape (Average \pm SD)

\begin{tabular}{llll}
\hline Gender & $\begin{array}{l}\text { Round shaped } \\
\text { mouth }\end{array}$ & $\begin{array}{l}\text { Oval shaped } \\
\text { mouth }\end{array}$ & p-Value \\
\hline Male & $74.25 \pm 12.34$ & $72 \pm 15.88$ & 0.65 \\
Female & $74.51 \pm 12.49$ & $74.32 \pm 9.87$ & 0.92 \\
Combined & $74.38 \pm 0.18$ & $73.16 \pm 1.64$ & 0.20 \\
\hline
\end{tabular}

( $p>0.05$ hence considered as non-significant)

\section{Conclusion}

It was concluded that the blood pressure had no scientific relation with the shape of mouth.

\section{Acknowledgment}

None.

\section{Conflicts of interest}

Author declares there are no conflicts of interest.

\section{References}

1. Trialists'Collaboration BP, Turnbull F, Neal B, et al. Effects of different regimens to lower blood pressure on major cardiovascular events in older and younger adults: meta-analysis of randomised trials. BMJ. 2008;336(7653):1121-1123.

2. Lip GY, Skjøth F, Overvad K, et al. Blood pressure and prognosis in patients with incident heart failure: the Diet, Cancer and Health $(\mathrm{DCH})$ cohort study. Clin Res Cardiol. 2015;104(12):1088-1096.

3. Qadir MI, Saleem A. Awareness about ischemic heart disease in university biotechnology students. Glo Adv Res J Med Medical Sci. 2018;7(3):5961.

4. Chin A, Xin X, He J. Exercise Lowers Blood Pressure. Ann Intern Med. 2002;136(7):493-503.

5. Turnbull F, Neal B, Algert C, et al. Effects of different blood pressurelowering regimens on major cardiovascular events in individuals with and without diabetes mellitus: results of prospectively designed overviews of randomized trials. Arch Intern Med. 2005;165(12):1410-1419.

6. Appel LJ, Moore TJ, Obarzanek E, et al. A clinical trial of the effects of dietary patterns on blood pressure. $N$ Engl J Med. 1997;336(16):11171124 . 